\title{
A THREE-DIMENSIONAL POLAR ICE-SHEET MODEL
}

\author{
By D. Jenssen \\ (Meteorology Department, University of Melbourne, Parkville, Victoria 3052, Australia)
}

\begin{abstract}
A three-dimensional model of the temperature and velocity distribution within any arbitraryshaped ice mass is described. There is a mutual interaction in the model between the flow of the ice and its thermodynamics, since the flow law used in the model is temperature-dependent.

Ice growth in three dimensions is governed by mass accumulation through precipitation, by mass depletion through loss of ice over the ocean, and by continuity requirements. Phase changes at the base of the ice are accounted for. The model has been applied in an exploratory manner to the Greenland ice sheet. Changes in the ice shape and temperature are presented and discussed. The basic shortcoming of the model as here presented appears primarily due to the coarse finite-difference mesh used, and to an unsophisticated approach
to modelling the boundary ice.

RÉsumé. Un modèle tridimensionnel de calotte glaciaire polaire. On décrit un modèle tridimensionnel de la distribution des températures et des vitesses dans une calotte glaciaire de forme arbitraire. Il y a dans le modèle une interaction mutuelle entre l'écoulement de la glace et sa thermodynamique puisque la loi d'écoulement utilisée dans le modèle dépend de la température.

$\mathrm{La}$ croissance de la glace dans trois dimensions dépend de l'accumulation par les précipitations, des pertes de glace dans les Océans et des lois de la continuité. On prend en compte les changements de phase à la base de la glace. Le modèle a été appliqué à titre exploration au Groenland. On présente et on discute les changements de forme et de température. Le défaut de base du modèle tel qu'il est présenté paraît en premier lieu dû à la maille grossière du système aux différences finies utilisé ainsi qu'à une approche peu perfectionnée de la modélisation des limites de la glace.

Zusammenfassung. Ein dreidimensionales Modell für polare Eisdecken. Es wird ein dreidimensionales Modell der Temperatur- und Geschwindigkeitsverteilung in einer beliebig geformten Eismasse beschrieben. Da das im Modell benutzte Fliessgesetz temperaturabhängig ist, besteht im Modell eine Wechselwirkung zwischen dem Eisfluss und seiner Thermodynamik.

Die Zunahme des Eises in drei Dimensionen wird von der Massenakkumulation durch Niederschlag, vom Massenverlust durch Kalbung in den Ozean und durch die Kontinuitätsbedingung gesteuert. Phasenwechsel am Untergrund des Eises werden berücksichtigt. Das Modell wurde versuchsweise auf das grönländische Inlandeis angewandt. Änderungen der Form und der Temperatur des Eises werden dargelegt und diskutiert. Der grundlegende Nachteil des Modells, wie es hier vorgestellt wird, scheint vor allem darin zu liegen, dass ein grobes Netz der finiten Differenzen benutzt und der Eisrand nur mit einer einfachen Annäherung erfasst wird.
\end{abstract}

\section{Introduction}

Historically, the first attempts to model glaciers by computer concerned the temperature distributions in polar ice sheets (Bogoslovskiy, I958; Jenssen and Radok, I96 I, I963). In these calculations, simple one-dimensional heat-conduction models were used to determine steady-state vertical temperature profiles. Later studies retained the one-dimensional system but introduced special transient states in which the velocities along a flow line were prescribed or determined from mass conservation and defined changing boundary conditions of temperature and accumulation rate. This made it possible to deduce areas of melting and freezing along the bedrock, trajectories of particles through the ice (and hence ages and residence times), temperature-dependent absorption rates for radar signals, etc. Full details may be found in Budd and others (197I).

A more recent development has been the computer modelling of glacier flow for the isothermal case in which the ice deformation may be assumed in first approximation to depend on stress alone, even though there is now ample experimental evidence that other factors such as crystal orientation and size, impurities and melt water play at least comparable roles. The first of these glacier-flow modelling calculations was carried out for a simple dynamical system in three dimensions by Campbell and Rassmussen (1970); later Budd and Jenssen ([r 975$])$ developed a two-dimensional model which includes longitudinal strain-rate differences in the balance of forces and deduces the flow velocity at any point from a theoretically based relationship in terms of the local ice thickness and surface slope which Budd and 
Allison ([1975]) showed to give a close approximation to the observed velocities of a number of well-documented glaciers.

The model of the present paper represents a first attempt at combining these main strands of glacier modelling by computer. It treats the mutual interaction of velocity and temperature in a three-dimensional coordinate system with realistic boundaries resembling those of a large polar ice sheet. The preliminary results are presented to test the model and identify computational problems which must be solved before a full-scale modelling experiment can be attempted on a large computer.

\section{Outline OF THE MODEL}

\subsection{The equations used}

The core problem is that of integrating the three-dimensional heat-conduction equations:

$$
\rho c \frac{\partial T}{\partial t}=\nabla k \cdot \nabla T-\rho c \mathbf{V} \cdot \nabla T+k \nabla^{2} T+\rho c q .
$$

Here $q$ (units $\mathrm{K} \mathrm{s}^{-1}$ ) is the heating within the ice due to friction, $T(\mathrm{~K})$ is the absolute temperature of the ice, $\rho\left(\mathrm{kg} \mathrm{m}^{-3}\right)$ is the density, $c\left(\mathrm{~J} \mathrm{~kg}^{-1} \mathrm{deg}^{-1}\right)$ is the specific heat capacity, $k$ $\left(\mathbf{W ~ m} \mathbf{m}^{-1} \mathrm{deg}^{-1}\right)$ is the thermal conductivity, and $\mathbf{V}$ is the three-dimensional velocity.

$$
\mathbf{V} \equiv \mathbf{i} u+\mathbf{j} v+\mathbf{k} w \equiv \boldsymbol{\nu}+\mathbf{k} w,
$$

where $u, v$ and $w$ are the components of velocity and $\mathbf{i}, \mathbf{j}$ and $\mathbf{k}$ are unit vectors along $x, y$ and $z$.

The coordinates for this equation are the common rectangular $(x, y, z, t)$ system with $z$ directed downwards from an origin at sea-level. Since the upper and lower boundaries of the ice are not horizontal-inasmuch as the surface is assumed to have any arbitrary shape, as does the bedrock beneath, and melting is a function of the computations - there will be parts of these boundaries which cross the axes, leading to difficulties in the computational stage when derivatives are replaced by finite differences. Furthermore, the changes in horizontal and vertical disposition of the ice (as the ice mass changes shape in time) will mean that some particular points of the finite-difference grid will sometimes be in air, sometimes in water, sometimes in ice. Thus boundary errors may be quite large unless great care is taken, generally by decreasing the grid size (and therefore the time step), and using highly accurate finite differences near the edges of the ice.

On the other hand, this problem may be overcome quite simply by a change in the vertical coordinate. The equations which result are considerably more complex than those above, but since the number of points in the grid does not have to be increased, nor the time step decreased, nor special finite differences applied near the boundaries, the computation is considerably quicker and more accurate.

A new coordinate, $\zeta$, is defined:

$$
\zeta \equiv \frac{z+M+F+D}{D}=\frac{E+z}{D},
$$

where $M$ is the total melt beneath the ice, $D$ is the depth of the ice, $F$ is the bedrock height and $E$ the ice surface elevation (all measured above the arbitrary, fixed reference level: sealevel). It is clear that all the ice is always contained between the levels $\zeta=0$ (the surface) and $\zeta=\mathrm{I}$ (the lower boundary between ice and water or ice and bedrock), and that as the ice grows or shrinks, the vertical coordinate automatically expands or contracts.

This "mapping" of the $(x, y, z, t)$ system into a non-orthogonal set of axes $(x, y, \zeta, t)$ is quite analogous to the $\sigma$-coordinate system developed by Phillips (1957) for numerical weather forecasting. Both new systems share the relative disadvantage that simple derivatives become transformed into much more complex forms. Techniques whereby these transformations may 
be developed will be omitted here, but may be found for example in Haltiner (I97I). It may be shown that:

$$
\begin{aligned}
\nabla_{z} T & =\nabla_{\zeta} T+\frac{\mathrm{I}}{D} \frac{\partial T}{\partial \zeta} \boldsymbol{\epsilon}, \\
\nabla_{z}^{2} T & =\nabla_{\zeta^{2}} T-2 \boldsymbol{\epsilon} \cdot \nabla_{\zeta}\left[\frac{\mathrm{I}}{D} \frac{\partial T}{\partial \zeta}\right]+\frac{\mathrm{I}}{D} \frac{\partial T}{\partial \zeta} \nabla \cdot \boldsymbol{\epsilon}+\frac{\mathrm{I}}{D^{2}} \frac{\partial^{2} T}{\partial \zeta^{2}} \boldsymbol{\epsilon} \cdot \boldsymbol{\epsilon}+\frac{\mathrm{I}}{D^{2}} \frac{\partial T}{\partial \zeta} \boldsymbol{\epsilon} \cdot \frac{\partial \boldsymbol{\epsilon}}{\partial \zeta},
\end{aligned}
$$

and

$$
\nabla_{z} k \cdot \nabla_{z} T=\nabla_{\zeta} k \cdot \nabla_{\zeta} T+\frac{\mathrm{I}}{D} \frac{\partial T}{\partial \zeta} \nabla k \cdot \boldsymbol{\epsilon}+\frac{\mathrm{I}}{D} \frac{\partial k}{\partial \zeta}\left(\nabla_{\zeta} T \cdot \mathbf{\epsilon}\right)+\frac{\mathrm{I}}{D^{2}} \frac{\partial T}{\partial \zeta} \frac{\partial k}{\partial \zeta} \mathbf{\epsilon} \cdot \mathbf{\epsilon},
$$

where $\nabla_{\zeta} \equiv \mathbf{i}(\partial / \partial x)+\mathbf{j}(\partial / \partial y)+\mathbf{k}(\mathrm{I} / D)(\partial / \partial \zeta), \boldsymbol{\epsilon} \equiv \nabla(E-\zeta D)$, and the subscripts refer to the coordinate systems. No subscript indicates independence of either set of axes.

The increased complexity of the terms of Equation ( $I$ ) in the $\zeta$-system involves only a moderate increase in programming and computation time, which is far outweighed by the very decided advantage of automatic removal of some of the more difficult boundary problems.

The following equations, needed to complete the model, will not be discussed in detail; their interpretation can be found in Budd and others (197I) and Budd and Jenssen ([1975]).

Heat input into the ice mass both from below and from internal viscous dissipation is given, for basal heating only, by

$$
\left[\frac{\partial T}{\partial \zeta}\right]_{\mathrm{b}}=D\left(\Gamma-\frac{\rho g D}{k}\left(\boldsymbol{\nu}_{\mathrm{b}} \cdot \nabla E\right)\right),
$$

where $g$ is the acceleration due to gravity, and $\Gamma$ is the geothermal heat flux. The second term represents the contribution made to the base gradient by frictional warming, in which $\nu_{\mathrm{b}}$ and $\tau_{\mathrm{b}}$ are the basal horizontal velocity and the base stress.

The heating by frictional dissipation inside the ice mass is

$$
q=\frac{g}{c} \nabla(E) \cdot \frac{\partial \boldsymbol{\nu}}{\partial \zeta},
$$

where $\partial \boldsymbol{\nu} / \partial \zeta$ has a number of analytic forms or is determined directly from the observed and experimental data. In this latter case the lower boundary condition is best chosen to be not Equation (4a) but rather

$$
\left[\frac{\partial T}{\partial \zeta}\right]_{\mathrm{b}}=\Gamma D
$$

Thus heating in the general case results from viscous dissipation and from the input to the base due to the geothermal heat flux.

When phase changes occur, Equations (4a) and (4c) are replaced by

$$
T_{\mathrm{b}}=T_{\mathrm{pm}}
$$

as a lower boundary condition. The pressure melting temperature $T_{\mathrm{pm}}$ may be taken (see, for example, Dorsey, r 940 ) to be a simple function of depth: $T_{\mathrm{pm}}=273 \mathrm{~K}-(0.0077 \mathrm{~K} / \mathrm{m}) \mathrm{D}$.

It may be shown quite readily (see Budd and others, 197I) that the amount of melt is simply proportional to the difference between the computed temperature gradient $[\partial T / \partial \zeta]_{\mathbf{c}}$ (using Equation (5)) and the basal heat input. Thus

$$
m=\frac{k}{\rho L D}\left\{\left[\frac{\partial T}{\partial \zeta}\right]_{\mathrm{b}}-\left[\frac{\partial T}{\partial \zeta}\right]_{\mathrm{c}}\right\} .
$$

Here $L$ is the latent heat of fusion, and $[\partial T / \partial \zeta]_{\mathrm{b}}$ is given by either Equation (4c) for generalized flow, or is given by Equation (4a) for columnar motion. The quantity on the right-hand side of Equation (6) is a positive quantity for melting, and negative for freezing. 
Continuity of mass for the local element, for the entire ice flowing through a column above the bedrock, and for the amount of melt water is governed by the equation

$$
\nabla_{z} \cdot \mathbf{V}=0 \quad \text { or } \quad D \nabla_{\zeta} \boldsymbol{\nu}+\mathbf{\epsilon} \cdot \frac{\partial \boldsymbol{\nu}}{\partial \zeta}=-\frac{\partial w}{\partial \zeta},
$$

(note that here $w=\mathrm{d} z / \mathrm{d} t$ and $n o t \mathrm{~d} \zeta / \mathrm{d} t$ ) and

$$
\frac{\partial D}{\partial t}=A-m-\nabla_{z}\left(D \int_{0}^{1} \nu \mathrm{d} \zeta\right),
$$

where $m$ is the instantaneous amount of melt, $m=\partial M / \partial t$, and $A$ is the surface rate of accretion (or ablation) of matter.

The total amount of melt at any location above the bedrock is simply:

$$
M=\int m \mathrm{~d} t,
$$

where $m$ is found from Equation (6).

Finally, as described by Budd and Jenssen ([1975]) the horizontal velocity at any point within the ice mass is found by integrating the shear strain-rate $\partial \boldsymbol{\nu} / \partial \zeta$ using a table of empirical values of that quantity as a function of temperature and stress. With the stress defined by:

$$
\tau=\rho g \zeta D \nabla(D+H),
$$

the table look-up is easily effected and leads to:

$$
\nu=D \int_{0}^{\mathrm{I}} \frac{\partial \boldsymbol{\nu}}{\partial \zeta} \mathrm{d} \zeta+\nu_{\mathrm{b}} .
$$

Here $\boldsymbol{\nu}_{\mathrm{b}}$ is the velocity at the lower ice boundary, and, for no slip, is zero.

With the horizontal velocity known, the vertical component of motion is found using the equation of continuity for an element of the ice (Equation (7)) and integrating vertically:

$$
w_{a}=-\int_{\mathrm{i}}^{\mathrm{a}}\left(D \nabla_{\zeta} \cdot \boldsymbol{\nu}+\boldsymbol{\epsilon} \cdot \frac{\partial \boldsymbol{\nu}}{\partial \zeta}\right) \mathrm{d} \zeta+w_{\mathrm{b}},
$$

where $w_{\mathrm{b}}\left(=\nu_{\mathrm{b}} \cdot \nabla H\right)$ is the vertical velocity at the base of the ice and $w_{a}$ is the $(x, y, z, t)$ vertical velocity at $\zeta=a$. Once again it must be remembered that $w=\mathrm{d} z / \mathrm{d} t$ and not $\mathrm{d} \zeta / \mathrm{d} t$.

\subsection{The flow law used}

As mentioned above, the horizontal velocity is determined by integration of the shear strain-rate, which is in turn a function of temperature and stress. The relation used is an empirical one, based on laboratory and field measurements, and presented in graphical form by Budd (1969) in his figure 2.2. For the model, the curves of that diagram were transformed into tabular form (Table I).

With stress computed by Equation (I0) and temperature computed through Equation (I), the Table allows strain-rate to be found for any point. Integration along a vertical in the mass (Equation (I I)) will give the horizontal velocity $v$ which is broken into its $x$ and $y$ components.

\subsection{Temperature conduction of bedrock}

Over long periods of time, the temperature profile in the underlying bedrock will vary with time in what may in all probability be a complex interaction with the temperature profile of the ice mass above. Since this pilot model was to be used to test its feasibility, and 
TABLE I. Logarithm of STRAin-RATE IN $^{-1}$ As A FUnCtion of STRESS AND TEMPERATURE

Temperature
${ }^{\circ} \mathrm{C}$
0
-5
-10
-20
-30
-40
-50
-60
-70

$\begin{array}{ll}-1.0 & -0.8 \\ -9.22 & -8.96 \\ -9.98 & -9.78 \\ -10.28 & -10.08 \\ -10.77 & -10.56 \\ -11.23 & -11.00 \\ -11.70 & -11.50 \\ -12.16 & -11.96 \\ -12.55 & -12.35 \\ -12.87 & -12.67\end{array}$

\begin{tabular}{cc}
\multicolumn{2}{c}{ Logarithm of octahedral } \\
-0.6 & -0.4 \\
-8.70 & -8.43 \\
-9.56 & -9.28 \\
-9.86 & -9.63 \\
-10.35 & -10.12 \\
-10.80 & -10.59 \\
-11.30 & -11.10 \\
-11.75 & -11.56 \\
-12.15 & -11.95 \\
-12.47 & -12.27
\end{tabular}

shear stres
-0.2
-8.12
-9.97
-9.38
-9.84
-10.37
-10.86
-11.36
-11.75
-12.03

0.0
-7.69
-8.62
-9.10
-9.56
-10.12
-10.60
-11.16
-11.55
-11.77

$\begin{array}{cc}0.2 & 0.4 \\ -7.07 & -6.23 \\ -8.14 & -7.66 \\ -8.71 & -8.29 \\ -9.23 & -8.82 \\ -9.82 & -9.42 \\ -10.31 & -10.00 \\ -10.87 & -10.53 \\ -11.35 & -11.00 \\ -11.75 & -11.41\end{array}$

was to be used only for short periods of time (less than 5 ooo years), heat conduction in the bedrock was ignored. There was, then, the further assumption that this effect was a secondorder one. On the practical side, inclusion of points in the bedrock would increase either (or both) the time of the computation or the number of points in the grid. Since both time and space of the computer used were being stretched simply by the basic model, the refinement of bedrock conduction was not added.

\section{Computational details}

\section{I. The basic procedure}

The use of the heat-conduction and continuity equations on a computer requires additional theory, amendment and information. The exact derivatives must be replaced by finite differences (so that a three-dimensional mesh must be chosen to cover the area of interest); the time step of the integration procedure must be consistent with the mesh intervals in order to avoid computational instability; and suitable boundary and initial conditions must be chosen. In addition, and with the object of saving computer time, the integration for this particular model does not proceed at the same pace for all grid points: some regions will have many integrative steps, with a small time interval, whilst others will have few steps, but with a large time interval.

The skeleton of the computational procedure is as follows:

(i) Assuming that temperatures everywhere within the grid are known (see below), the velocity distribution (both horizontal and vertical) is computed.

(ii) With a value for the time step involved in the integration correctly chosen so as to satisfy the stability criterion at the given location (see below), the temperature changes within the ice are found and hence the new temperature distribution is determined. The heatconduction equation used for this step is a modified and simplified form of Equation ( $\mathrm{I}$ ) in the $\zeta$-coordinate system.

(iii) The continuity equations for depth and melt are then satisfied, and any base temperatures in need of correction are adjusted.

(iv) The ancillary computation of trajectory locations is made.

(v) Steps (i) to (iv) are repeated until the integration time is some arbitrary amount.

(vi) The ancillary computation of dielectric absorption, both per unit depth and throughout the entire ice depth, is made.

(vii) Relevant parameters are then printed out. These include the two-dimensional fields: surface and basal temperature distribution; minimum temperatures at all verticals within the ice, and the depth at which these low values occur; the surface and basal computed temperature gradients; distribution of melt water; the mean temperature of the ice in any vertical; the effective "mean absorption temperature", that is the temperature a column would have to have, if, when isothermal, the dielectric absorption were to be the same 
as that computed at that location; the surface horizontal streamlines; and the vertical velocity distribution. See Budd and others (1971) for a further discussion of these quantities.

Another important output statistic is the mass budget for the entire ice mass-and this includes accumulation and ablation areas, loss due to melting, and loss of ice at the horizontal edges of the ice due to "calving". Local mass budgets for regions of particular interest are also made. Floating ice, attached to the main mass, is followed until calving occurs.

(viii) The process recycles back to step (i) until the full computation time has been reached.

The computational problems involved in this procedure are discussed in detail in a separate report (to be published by D. Jenssen). The main problems concern the stability of the finite-difference algorithms and the parameterization of the spread of the ice sheet over the oceans.

\subsection{Computational stability}

For the simple one-dimensional case, it can be shown that in order to preserve stability and to damp errors, preventing their exponential growth, the time and space increments must satisfy the following relation:

$$
\Delta t<\min \left[\frac{3 D^{2} \Delta \zeta^{2}}{8 K^{2}}, \frac{2 K}{A^{2}}\right] .
$$

The non-linearity, and three-dimensional nature, of Equation ( $\mathrm{I}$ ) make the determination of its stability criterion very much more difficult. However, if it is realized that the time step depends on the smallest grid spacing, which is the vertical, then Inequality (13) must be a good approximation to the true stability criterion. (The horizontal spacing is measured in tens of kilometres, the vertical in tens of metres.) The non-linearity of the heat-conduction equation will probably reduce the maximum time step slightly, if at all. Pragmatically, Inequality (13) has been used in the preliminary three-dimensional model calculations to determine the maximum time step which can safely be used, and no evidence of computational instability has been found. With Inequality (13) violated, however, forward time integration did in fact very quickly lead to the meaningless results typical of computational instability.

Now examine the stability criterion (13) in more detail. Since the number of points in the vertical is the same for all points of the grid, $\Delta \zeta$ is constant, and thus the time step, $\Delta t$, is roughly proportional to the square of the ice thickness. It would appear that to avoid computational instability, the choice of the time step is governed by the thinnest ice which will be encountered in the grid which has been arbitrarily set at $50 \mathrm{~m}$. If, say $50 \%$ of the ice is of reasonable thickness, then a large time step ( 100 years or so) may be used. For the thinnest ice, which probably will not occupy more than a maximum of $10 \%$ of the grid, the time step must be less than I year-and may even drop to o. I years. Thus if the same value of $\Delta t$ is used over the entire mesh, gross inefficiency in computation time will result: the heat conduction equation for the points of thick ice will be integrated perhaps a thousand times when in fact one integration with a value of $\Delta t$ a thousand times larger would have produced the same temperatures.

To avoid this inefficiency, different values of the time step were used in regions of different ice thickness, so that if the largest time step permissible anywhere in the grid is $\Delta t_{\max }$, then at any arbitrary point the time step $\Delta t$ is such that $\Delta t_{\max }=\mathcal{N} \Delta t$, where $\mathcal{N}$ is an integer. This means that while the integration proceeds at different paces in different spots, every $\Delta t_{\max }$ all these independent integrations "mesh" together. Of course, none of the $\Delta t$ used violate the stability criterion, so that not only is computational stability preserved, but also the computation of temperatures proceeds everywhere at an optimum speed. 


\subsection{Changes in horizontal extent of the grid}

During the course of the computation, as the ice grows or shrinks horizontally, or as it flows over the ocean, the type of material at a grid point may change, so that the computations performed there will change in frequency and nature, and "shocks" at the boundary may be set up. The coarser the grid, the more severe will be these shocks, unless special "tracking" procedures (equivalent to having a very fine grid along the boundaries of the more coarse one) are utilized.

For any complete study, the ice flow past the grid boundaries must be treated from time step to time step, much in the same manner as the glacier snout was followed computationally in the model of Budd and Jenssen ([1975]). For the present preliminary three-dimensional computations, however, no such treatment has been made. The discussion of the results obtained (see below) will show the effect of neglecting this.

\subsection{Ice shelves and calving icebergs}

As mentioned earlier, the minimum ice depth considered has been about $50 \mathrm{~m}$. Any thinner ice results in so small a time step that computation time becomes prohibitively largeespecially when it is noted that total integration times of the order of hundreds of thousands of years may be required.

This restriction can of course be varied according to the size of the ice sheet, and with the times over which an integration is to be performed. It has the advantage of allowing calving to be treated in a very simple manner. Whenever the depth becomes smaller than the cut-off value chosen, all ice at that point is removed from the grid (provided that the point is in the ocean and that at least one of its eight closest neighbours is also in the ocean, and has a depth less than the minimum figure). The ice removed in this manner is thought of as a detached iceberg, and is no longer treated.

If the ice depth is less than $50 \mathrm{~m}$ but the point is over the bedrock, or if all its neighbouring points have ice thicker than this minimum figure, the point in question merely represents a local deep depression, and cannot possibly calve away from the main ice mass. Such special points are tagged, and either arbitrary temperature distributions assigned to them (of a steady-state nature) or they are given temperatures which are weighted averages of the surrounding ice temperatures. Thus velocities may be computed for these anomalous points, and continuity requirements may be satisfied as well. In this manner ice may grow over the bedrock, or extend, without calving, over the oceans to form ice shelves.

For the ice over the land, the temperature and velocity are not computed by the main equations of the model until the thickness exceeds $50 \mathrm{~m}$. Over the sea, ice velocity and temperature are always weighted averages of the surroundings. This simplistic approach to ice-shelf dynamics and thermodynamics is one feature of the model which must be treated more realistically in any larger-scale study.

\section{Results}

\section{I. Grid, time steps, initial conditions}

The model outlined above has been tested by means of a coarse representation on the Greenland ice sheet. For this pilot study an IBM 7044 machine was used. Its restricted capacity imposed the choice of a $12 \times 12 \times 10$ (vertical) point grid; the east-west grid spacing was $100 \mathrm{~km}$, the north-south spacing $200 \mathrm{~km}$, while the vertical spacing varied from 5 to
$300 \mathrm{~m}$.

The boundary of this grid is shown in Figure I. Also shown in this figure is the land extent of the grid: any points between the interior and exterior boundaries were considered to be oceanic. This is obviously not true for those points midway on the east coast of Greenland, 

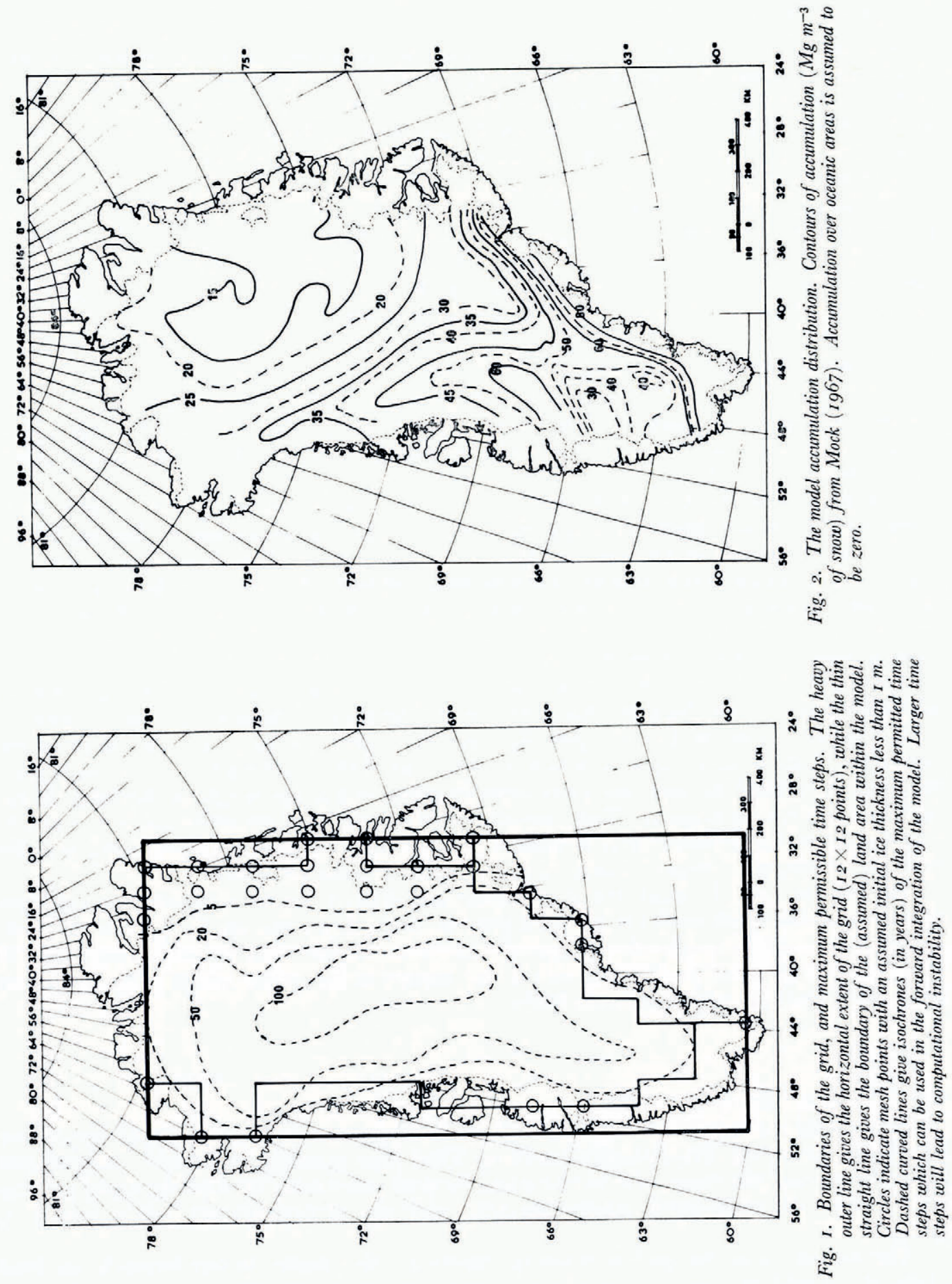

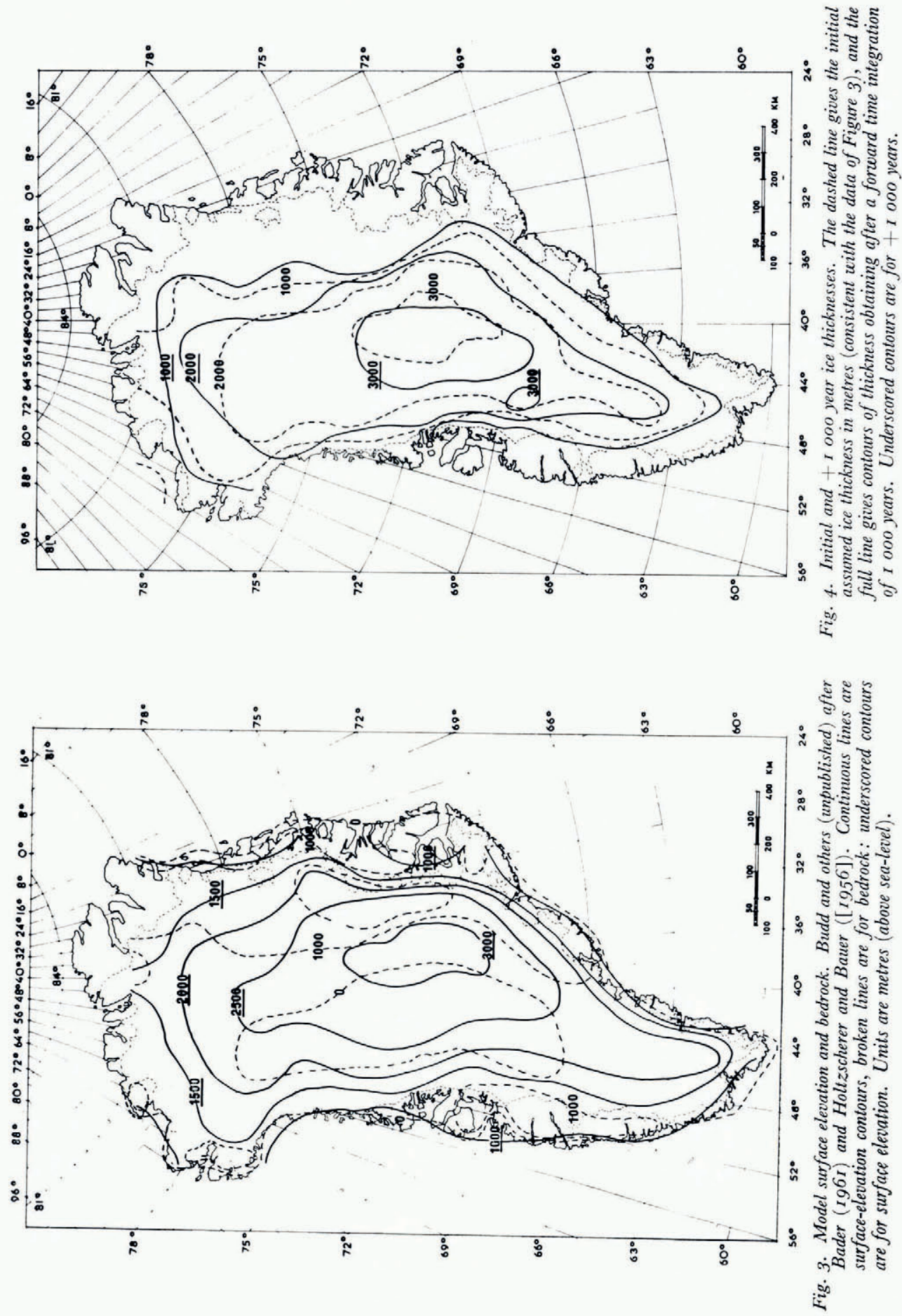

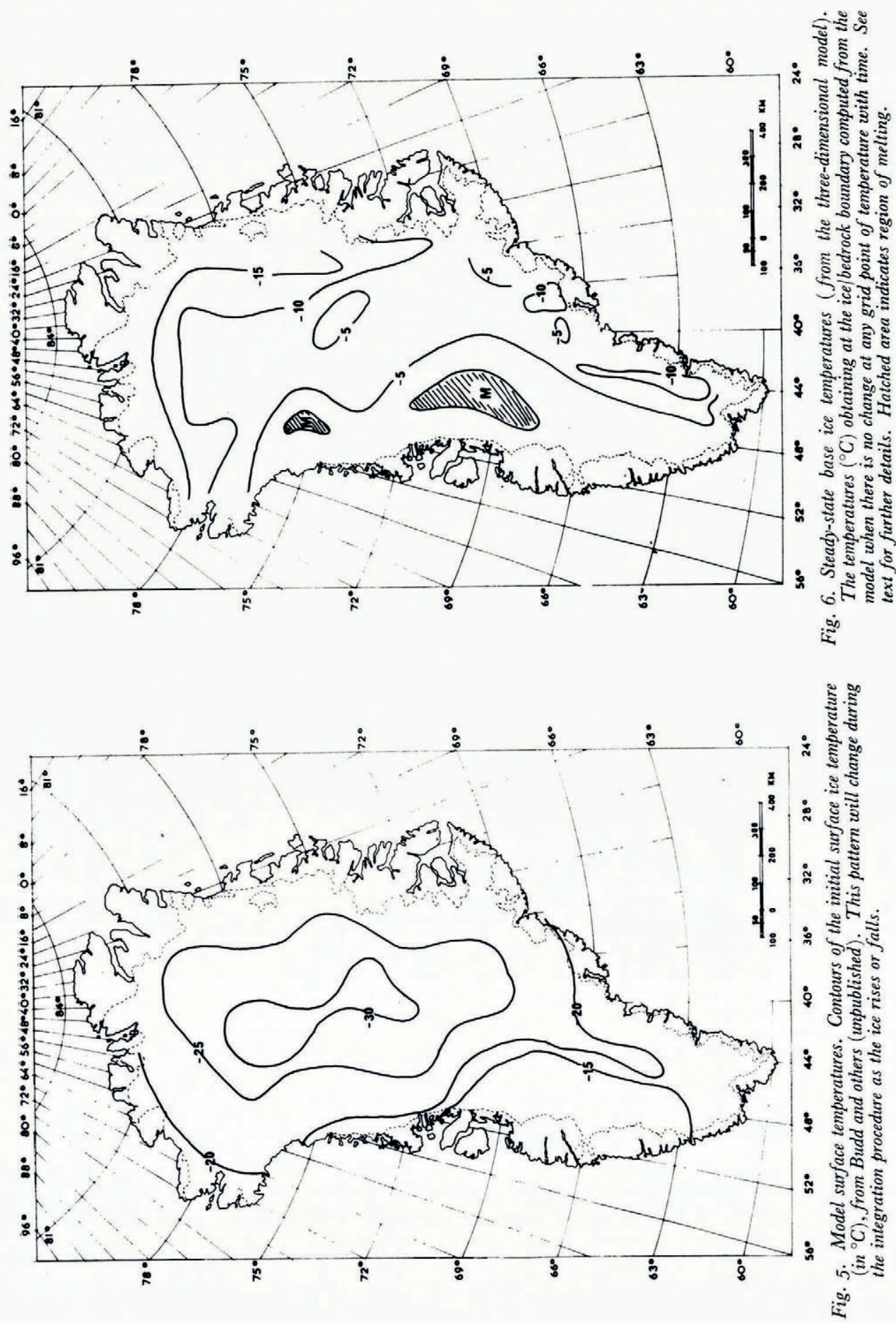
but the main purpose of this preliminary study was a thorough testing of the model and of the program based on it. The uneven land boundary on eastern Greenland was deliberately chosen to examine the effects of various backward finite-difference operators on the calculations. Note the almost isolated point seven rows from the northern boundary: a similarly isolated point exists at the southernmost land point of the Greenland grid.

Another feature of Figure $\mathrm{I}$ is that those grid points which initially had no ice (thickness less than $50 \mathrm{~m}$ ) are shown as open circles. Figure I also shows isochrones of the initial time step (which changed with the ice thickness during the integration). In order to speed up the computation, points with less than $50 \mathrm{~m}$ of ice and with local time-step values less than $\mathrm{I} \%$ of the maximum permissible for the grid were assigned steady-state temperatures or the average of the surrounding temperatures, and treated only in the continuity equation, until both the ice thickness exceeded $50 \mathrm{~m}$ and the local time step had become larger than $1 \%$ of the permissible grid maximum.

The surface accumulation, based on Mock (1967) is shown in Figure 2. Oceanic values were assumed to be zero in the pilot calculation; this produced strong accumulation gradients along the western and south-eastern coasts and had important effects on the calculations.

Figure 3 shows the bedrock (broken lines) and surface elevation contours (solid lines) used in this study. These are based on data from Bader (I96I) and Holtzscherer and Bauer ([1956]). The corresponding ice thickness distribution is given in Figure 4 as the dashed lines: the solid lines are computational results, and are discussed below.

Surface temperature is a boundary condition; values of this parameter are given in Figure 5 , based on data in Mock and Weeks (1965). However the full temperature field must initially be prescribed, and this distribution should be consistent with the model equations, in order to avoid spurious rates of temperature change which may amplify during the time integration (especially in view of the velocity/temperature feedback) to produce eventually small but significant variations in the temperature and motion fields.

To prevent this from happening, the initial temperatures were computed with the onedimensional steady-state model of Budd and others (I97I), and used as a first guess to the true temperatures by inputting them to the three-dimensional model. The surface temperature was forced to be constant in time, and, as well, no change in the shape, extent, or thickness of the ice field was allowed. Mass outflow from the edge of the ice was permitted, however. With these restrictions, the temperature distribution adjusted so that $\partial T / \partial t$ at any point decreased in magnitude and approached zero, that is reached a steady state. Since the velocity distribution was still being calculated (and used as a source of frictional heating), it remained consistent with the temperature pattern.

This computational approach to the steady state is rather slow: for the present case, some 120000 years of simulated time were required to have a rate of change in temperature everywhere of less than o.or deg/roo years.

It is not feasible to show graphically the entire three-dimensional temperature field, but a sensitive parameter which has been extensively used in previous studies is the basal temperature. This is shown in Figure 6, and, for comparison, the initial basal temperatures of the one-dimensional steady-state model are given in Figure 7 . Considerable differences in the extent of basal melting are indicated between the (assumed) initial and (computed) steady states; these are due almost entirely to the coarse nature of the vertical grid which could not cope adequately with the rapidly changing temperature gradients, and hence heat fluxes, near the base of the ice. Even so the actual temperature differences are only of the order of a few degrees and readily reducible (though not completely removable), by increasing the vertical resolution.

The velocity distribution corresponding to the computed temperatures is shown in Figure 8; broken lines give the initial value and full lines those developing subsequently. For compari-. son Figure 9 gives the velocities deduced from assuming a balanced mass flow over Greenland. 

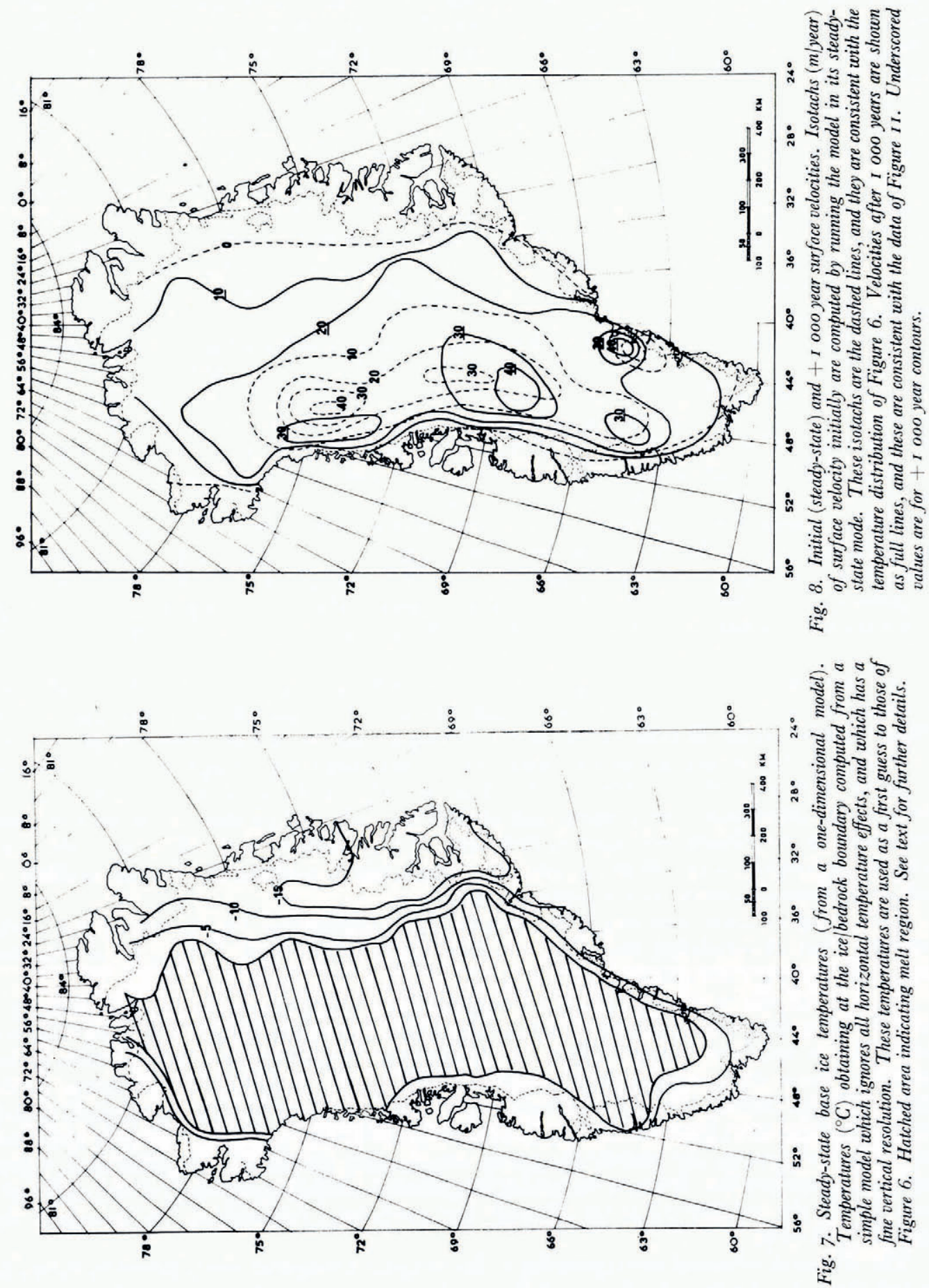

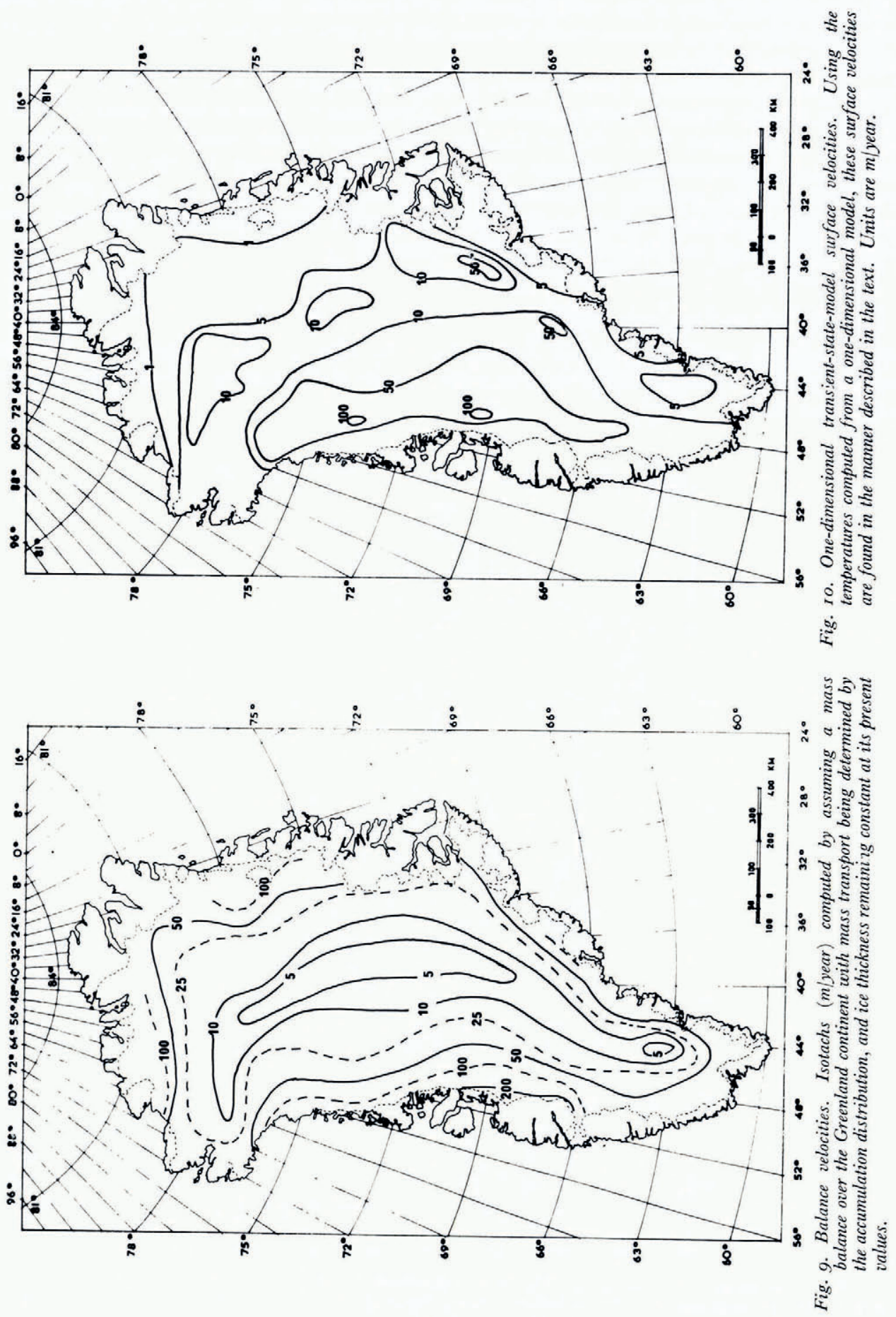
Both patterns show a region of very high velocity near the west coast with quite low velocities over the central and part of the eastern portion of Greenland. The computer model is unable to match velocities along the east coast because the ice there is so thin that it is excluded from the velocity computations.

Apart from this difference there remain enough discrepancies between Figures 8 and 9 to suggest that the ice velocity distribution in the Greenland ice sheet is not consistent with the assumption of balanced flow. This is further underlined by the results of a transient onedimensional temperature and velocity calculation along the lines described by Budd and others (197I). The resulting velocities are reproduced in Figure ro and (disregarding magnitudes which involve a simple adjustable parameter) the general pattern is very close to that of the computed steady-state velocities in Figure 8.

\subsection{Results of a I ooo year calculation}

With the grid initial inputs and time steps of Section 4.1 , the integration of the basic equations (Section 2) allows temperatures, velocities, ice shape, and ice extent to be computed at any future time.

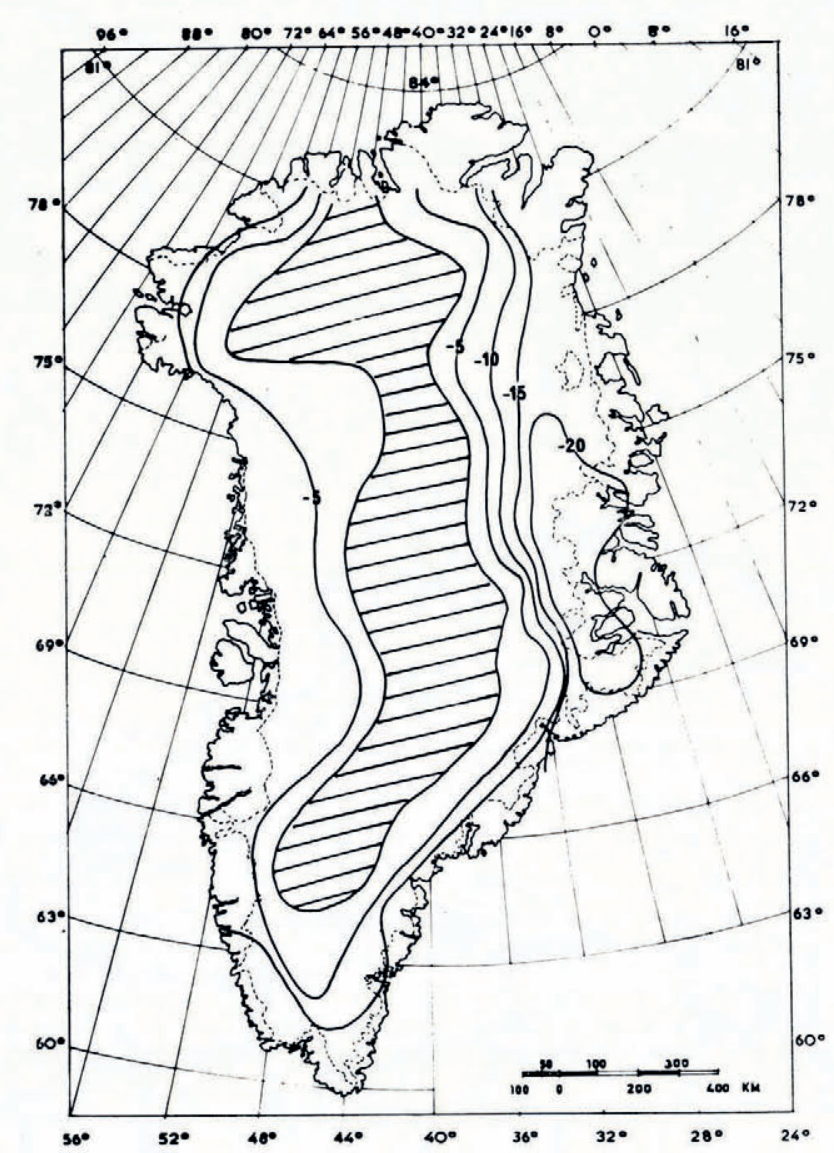

Fig. II. Base temperatures after $I$ ooo years. The basal temperatures $\left({ }^{\circ} \mathrm{C}\right)$ obtained by a forward time integration of $I$ ooo years. These are consistent with the ice thickness data of Figure 4 , and the isotach pattern of Figure 8 . Hatched area indicates basal temperatures greater than the pressure melting point. 
The full lines in Figure 4 show the ice thicknesses which have developed after I ooo years of unrestricted flow. The 3 ooo $\mathrm{m}$ contour has enlarged, and the maximum thickness of the ice has shifted slightly towards the west, where all ice thicknesses have increased markedly. Growth of the ice to the east has not been nearly so pronounced, due to the thinner and colder ice there, which will lead to much smaller velocities - see also Figure 8 . A very rapid build-up of ice has occurred to the west at about lat. $68^{\circ}$ where a small pocket of depths greater than 3 ooo $\mathrm{m}$ can be observed. This points out a deficiency in the present model associated with the very coarse grid used (I0o km west to east and $200 \mathrm{~km}$ north to south): in the integration of the continuity equation, the large distances over which the finite differences are taken tend to produce a smoothing effect, and to reduce the mass flow at any particular point. Near the edges of Greenland, in spite of allowing mass transfer to the oceans, this will produce the bank-up of material of Figure 4 .

The base temperatures (Fig. I I) show an interesting phenomenon over the west of Greenland; due to the increased ice thicknesses and higher surface elevations, the consequent decrease in surface temperatures has produced a marked decrease in base temperature, and contracted basal melting to a much narrower region. In fact on the west coast the temperatures have fallen to below $-5^{\circ} \mathrm{C}$. The velocities at $\mathrm{I}$ ooo years (full lines in Figure 8 ) show a general increase over most of Greenland and a somewhat more complex pattern with the formation of a region of high speeds to the south-west. The areas of greatest velocity near the coast also correspond to the growth of oceanic ice shelves.

\section{Discussion}

Since Figure i i shows that the base of the ice has cooled near the western extremities, the velocity increases there must be due to the greater ice thickness with the consequent increased
surface slopes.

On the other hand the rapid decrease of velocity between these maxima and the edge of the grid arises directly from the colder ice temperatures. This slowing down of the ice flow will also contribute to the banking-up of the ice near the coast.

We have therefore the following sequence of events for this particular case: due largely, it is thought, to the coarse grid, but also to the accumulation distribution and possibly the flow law used, the ice grew rapidly near the west coast; the surface slope increased and so therefore did the velocity; at the coast, however, the increased surface elevation led to colder temperatures and lower velocities - the ice flow was impeded; the ice depth increased and the surface slope increased; and so forth. Thus the velocities near the coast became larger rapidly, whilst those at the coast did not increase so quickly, and mass accumulated at the western edge of
Greenland.

Restated, in computational terms for the inadequate form of the model here considered:

(i) The coarse vertical spacing leads to incorrect lower temperatures, with the implication of large heat inputs: this, in turn, will lead to a spuriously high velocity distribution.

(ii) The coarse horizontal spacing leads to smoothing out of features inland with a consequent lowering of velocity there.

(iii) The coarse horizontal spacing near the coast exaggerates the surface slope, and hence the velocity, creating a large mass flow. This is prevented from leaving the grid because

(iv) the coarse horizontal spacing at the coast, coupled with the inferior method of allowing for floating ice shelves cannot transport mass away from the central land mass.

(v) The coarse horizontal spacing also contributes to the mass barrier on the west because it implies a large horizontal gradient of accumulation near the coast.

These deficiencies of the model interact with each other in an unstable feed-back mechanism so that mass builds up excessively on the western coast ever more quickly. Shortly 
after $\mathrm{I}$ ooo years, in fact, the surface slopes computed within the model became so large that the concomitant base stresses exceeded the maximum allowed for in the table, and the computation was terminated.

On the credit side it may be claimed that the equations of the model are realistic since they lead to three-dimensional distributions of temperature and velocity consistent with those obtained from two other, independent, one-dimensional models (the steady and transient state models of Budd and others (I97I)). Differences between these three models are merely those to be expected when a basic model is successively made more realistic and hence more complex.

For the first time, velocity and temperature have been made mutually interactive for a three-dimensional ice mass, and their distributions at any time are consistent in regard to temperature, motion, continuity, ice thickness, and mass flow. Moreover the model permits the generation of floating ice to be followed, as well as mass loss by calving.

\section{OutLook}

The non-realistic character of the results presented has been found to be directly attributable to the coarse grid used in the study - this in turn being dictated by the computer which was employed. Clearly future calculations must use a very much finer grid, both horizontally and vertically, together with the corresponding smaller time steps and superior forms of finite difference analogues.

Once the troubles arising from the coarse grid are removed, there still remains much experimental and exploratory work in order to determine the effects of various parameters. The results of the calculations may be found to be critically sensitive to changes in values of some of these, not so to others. Experimentation will determine those whose value must be specified accurately, and may show how the computations could be simplified for those which have only secondary effects on the results. In this area, the following must be studied:

(i) the heat input: integrations with both basal and layer frictional heating;

(ii) phase changes: incorporated, parameterized, or ignored;

(iii) horizontal derivatives: all incorporated, some incorporated, or all ignored;

(iv) continuity: used at every time step, or only once every $n$ time step;

(v) geothermal heat flux: constant everywhere, or point variable;

(vi) carrying the computation into the bedrock: changes in the bedrock/ice interface temperature will of course affect the heat influx, and over long periods can lead to significant changes in the boundary ice temperature;

(vii) treatment of the flow of the melt water;

(viii) lubrication of the ice by melt water: the decreased basal stress which results.

These are purely physical considerations; computational experimentation must include:

(i) stability: is relaxation of the criterion possible? If so, by how much?

(ii) the minimum ice thickness: what should this be?

Once this exploration has been accomplished, computational procedures clarified, and some parameterization formulated (if this is possible), the flow law must be thoroughly studied. The values of its parameters must be changed and the resulting distributions analysed. Its form also may need modification. Over the oceans, various flow models, of increasing subtlety, must be treated. Clearly a good deal of ground remains to be covered before the behaviour of the polar ice sheets can be adequately modelled.

MS. received I Fuly 1974 and in revised form 3 March 1977 


\section{REFERENCES}

Bader, H. 196r. The Greenland ice sheet. U.S. Cold Regions Research and Engineering Laboratory. Cold regions science and engineering. Hanover, N.H., Pt. I, Sect. B2.

Bogoslovskiy, V. N. 1958. The temperature conditions (regime) and movement of the Antarctic glacial shield. Union Géodésique et Géophysique Internationale. Association Internationale d'Hydrologie Scientifique. Symposium de Chamonix, I6-24 sept. 1958, p. 287-305. (Publication No. 47 de l'Association Internationale d'Hydrologie
Scientifique.) Budd, W. F. 1969. The dynamics of ice masses. ANARE Scientific Reports. Ser. A (IV). Glaciology. Publication
No. ro8.

Budd, W. F., and Allison, I. [1975.] An empirical scheme for estimating the dynamics of unmeasured glaciers. [UUnion Géodésique et Géophysique Internationale. Association Internationale des Sciences Hydrologiques. Commission des Neiges et Glaces.] Symposium. Neiges et glaces. Actes du colloque de Moscow, aout I97I, p. 246-56. (IAHS-AISH
Publication No. I04.)

Budd, W. F., and Jenssen, D. [1975.] Numerical modelling of glacier systems. [Union Géodésique et Géophysique Internationale. Association Internationale des Sciences Hydrologiques. Commission des Neiges et Glaces.] Symposium. Neiges et glaces. Actes du colloque de Moscow, août I97I, p. 257-91. (IAHS-AISH Publication No. I04.)

Budd, W. F., and others. 1971. Derived physical characteristics of the Antarctic ice sheet. Mark I, by W. F. Budd, D. Jenssen and $U$. Radok. Melbourne, University of Melbourne, Meteorology Dept. (University of Melbourne. Meteorology Dept., Publication No. 18.)

Budd, W. F., and others. Unpublished. The derived physical characteristics of Greenland, by W. F. Budd, D. Jenssen and F. Jacka. [Written 1974.]

Campbell, W. J., and Rasmussen, L. A. 1970. A heuristic numerical model for three-dimensional time-dependent glacier flow. [Union Géodésique et Géophysique Internationale. Association Internationale d'Hydrologie Scientifique.] [International Council of Scientific Unions. Scientific Committee on Antarctic Research. International Association of Scientific Hytrolsgy. Commission of Snow and Ice.] International Symposium on Antarctic Glaciological Exploration (ISAGE), Hanver, New Hampshire, U.S.A., 3-7 September 1968, p. 177-90. (Publication No. 86 [de 1'Association Internationale d'Hydrologie Scientifique].)

Dorsey, N. E. 1940. Properties of ordinary water-substance in all its phases: water-vapor, water and all the ices. New York, Reinhold Publishing Corporation. (American Chemical Society. Monograph Series, No. 8I.)

Haltiner, G. J. 1971. Numerical weather prediction. New York, John Wiley and Sons, Inc.

Holtzscherer, J.-J., and Bauer, A. [1956.] Contribution à la connaissance de l'inlandsis du Groenland. Première partie: Mesures séismiques par Jean-Jacques Holtzscherer. Deuxième partie: Synthèse glaciologique par Albert Bauer. Union Géodésique et Géophysique Internationale. Association Internationale d'Hydrologie Scientifique. Assemblée générale de Rome 1954, Tom. 4, p. 244-96. (Publication No. 39 de l'Association Internationale d'Hydrologie.)

Jenssen, D., and Radok, U. 196r. Transient temperature distributions in ice caps and ice shelves. Union Géodésique et Géophysique Internationale. Association Internationale d'Hydrologie Scientifique. Assemblée générale de Helsinki 25-7-6-8 196o. Colloque sur la glaciologie antarctique, p. 112-22. (Publication No. 55 de l'Association Internationale d'Hydrologie Scientifique.)

Jenssen, D., and Radok, U. 1963. Heat conduction in thinning ice sheets. Fournal of Glaciology, Vol. 4, No. 34, p. $387-98$.

Mock, S. J. 1967 . Calculated patterns of accumulation on the Greenland ice sheet. Fournal of Glaciology, Vol. 6, No. 48 , p. $795-803$.

Mock, S. J., and Weeks, W. F. 1965. The distribution of 10 meter snow temperatures on the Greenland ice sheet. Journal of Glaciology, Vol. 6, No. 43, p. 23-41.

Phillips, N. A. r957. A coordinate system having some special advantages for numerical forecasting. Fournal of Meteorology, Vol. 14, No. 2, p. 184-85. 